\title{
ESTUDO DA CONECTIVIDADE ENTRE O NERVO OCCIPITAL MAIOR E ESTRUTURAS ADJACENTES
}

\author{
CONSIDERAÇÕES ANÁTOMO-CLÍNICAS
}

CLARICE TANAKA * - WALTER BIAZOTTO * - RENATO P. CHOPARD * MARCílIo HUBNER DE MiRANDA NETO * - GUILHERME DE ARAÚJO LUCAS *

RESUMO - A fim de oferecer substrato anatômico que contribua para a interpretação clínica da cefaléia de origem cervical, estudo macro-mesoscópico do nervo occipital maior e da sua região de emergência subcutânea foi realizado. Observamos que, ao longo de sua estratigrafia, esse nervo descreve ângulos e mudanças de direção, que podem representar ponto a artéria e a veia occipital, feixe vásculo-nervoso envolvido por bainha de tecido conjuntivo fibroso, a qual mantém relações de continuidade e contigüidade com epimísio e perimísio adjacentes. A partir dos resultados encontrados, fazemos considerações anátomo-clínicas. Study of connectivity between greater occipital nerve and its adjacent structures: anatomo-

SUMMARY - In order to offer anatomical basis that aid for clinical interpretation of headache of cervical origin a macro-mesoscopic study of greater occipital nerve and it subcutaneous rise out site was accomplished. The authors observed that in its course this nerve dellneates angles and diection shifts that can stand for critical points in etiology of occipital pain, so that nin subcutaneous rise out region both occipital artery and vein shap the vity results, anatomo-clinical aspects are discussed.

Clinicamente a cefaléia de origem cervical tem território definido, cia região occipital à órbita, este aspecto podendo justificar cefaléias de origem mecânica pela a literatura surpreendemo-nos com grande número de estudos que são, entretanto, pouco conclusivos 5,6.8,9,11,13,14,17-19.

Hunter e Mayfield (1949) relatam que o movimento de extensão e rotação da cabeça coloca em contato os arcos posteriores do atlas e do axis, podendo comprimir o nervo occipital maior contralateral ao movimento. Bartschi-Rochaix (1968) cita que as cefaleias occipitais podem decorrer de compressão de artéria vertebral na região do forame entre $\mathrm{Cl}$ e $\mathrm{C} 2$ levando à isquemia os territorios dos ramos que suprem a dura-máter da fossa posterior do vinentos vertebrais sobre as raízes de $\mathrm{C}_{2}$, afirm que a unica possibilidade de compressão

* Departamento de Anatomia do Instituto de Ciências Biomédicas da Universidade de São Paulo (USP)

Dr. Renato P. Chopard - Departamento de Anatomia, Faculdade de Medicina USP - Av. Dr. Arnaldo 455 - 01246 São Paulo SP - Brasil. 
radicular a esse nível é na presença de associação de extensão e rotação extrema, em condições não exequíveis, comprimindo a raís contrialateral. O mesmo autor, em 1982, descreve que o nervo occipital maior e a artéria occipital deixam o plano profundo do músculo trapézio para entrar no couro cabeludo, não perfurando este músculo, mas passando sobre uma alça aponeurótica. Nessa região, o nervo e a artéria são revestidos por faseia subcutânea relativamente densa que desce do couro cabeludo para recobrir os músculos dorsais do pescoço. O autor considera que o espasmo do trapézio pode tracionar a ponte aponeurótica deste músculo para baixo e para longe do nervo occipital maior, não podendo, assim, ocasionar a neuralgia. Zaitseva \& Chudnovsky (1983) estudaram as relações anátomo-topográficas da artéria vertebral, músculos, nervos e tecido conjuntivo na região da articulação atlanto-occipital com técnicas de secção histotopográfica em cadáveres de fetos, recém-nascidos e indivíduos adultos. As estreitas relaçõesi dessas estruturas criam, segundo esses autores, condições de compressão vásculo-nervosa na região da articulação atlanto-occipital. Sjaastad e col. (1983) citam evidências para a origem cervical de certo tipo de cefaléia: a precipitação dos sintomas ocorre com movimentos do pescoço ou com pressões em determinados pontos dessa região: esta movimentação é acompanhada de crepitação e dor no local; a mobilidade é reduzida a esse nível; o bloqueio anestésico a nível da raiz de C2 e, eventualmente, de C3 alivia os sintomas. Bogduk e coL (1985) realizaram revisão visando a afastar distorções sobre a cefaléia «cervicogênica», definindo-a como cefaléia devida a alterações em estruturas do pescoço, como articulações, ligamentos ou outros tecidos associados a anormalidades de movimentos de segmentos vertebrais cervicais; os músculos, como o esternocleidomastóideo e o trapézio, bem como todos os que têm inserção na protuberância occipital, podem estar direta ou indiretamente envolvidos. Sjaastad e col. (1986) delineiam diferenças entre as várias formas de cefaléias cervicais segundo sua etiologia ou patogenicidade. Discutem também o alívio dos sintomas diante do bloqueio anestésico na região do nervo occipital maior.

Torna-se, pois, justificada a necessidade de investigação da conecticidade regional do nervo occipital maior e suas correlações anátomo-clínicas, dada a importância que se dá atualmente em clínica para as patologias dessa região.

\section{MATERIAL* E MÉTODOS}

A. Estudo macroscópico do trajeto do nervo occipital maior, desde sua origem no segundo nervo cervical até suas primeiras ramificações subcutâneas — Foram dissecados os dois lados das regiões occipital e póstero-lateral do pescoço de 5 cadáveres adultos formolizados. de ambos os sexos. As dissecções procederam dos planos superficiais para os profundos e, plano a plano, seguiu-se o trajeto do nervo occipital maior, anotando-se suas conexões fasciais, a sintopia vásculo-nervosa, as mudanças de direção e curvaturas nos planos frontal e sagital, locais de emissão de ramos, pontos de emissão de ramos, pontos de perfuração de faseias ou ventres musculares, estratigrafia e esqueletopia.

B. Estudo mesoscópico por cortes seriados espessos da região da emergência subcutânea do nervo occipital maior - Foram utilizadas 8 peças sem alterações locais, obtidas de necropsias de indivíduos adultos de ambos os sexos. Essas peças foram retiradas obedecendo superiormente a linha transversal traçada entre pontos marcados $2,0 \mathrm{~cm}$ acima de cada um dos meatos acústicos externos e, inferiormente, à linha transversal traçada $1,0 \mathrm{~cm}$ abaixo dos processos mastóides. Os limites lateral e medial para a obtenção das peças foram demarcados por segmento de $2,0 \mathrm{~cm}$ a partir da protuberância occipital em direção ao processo mastóide homolateral. A seguir, as peças foram reduzidas a blocos medindo $1,5 \mathrm{~cm} *$ de modo a conter a veia e a artéria occipital, o nervo occipital maior e os tecidos adjacentes Os blocos foram fixados em formalina a $10 \%$ e incluídos em parafina para cortes seriados espessos horizontais de $20^{\wedge} \mathrm{m}$, e corados pelos métodos do Azo-Carmim para feixes de fibras colágenas e Weigert para feixes de fibras elásticas. Os cortes foram analisados sequencialmente, com auxílio de microscópio Zeiss, procurando-se observar o comportamento dos componentes colágeno e elástico da região de emergência subcutânea do nervo occipital maior.

\section{RESULTADOS}

A. Estudo macroscópico do trajeto do nervo occipital maior, desde o, sua origem no segundo nervo cervical até suas primeiras ramificações subcutâneas — Segundo as relações de sintopia o trajeto do nervo occipital maior pode ser descrito em duas porções; 
1. Porção profunda - Estende-se desde sua origem no segundo nervo cervical até o plano subaponeurótico do músculo trapézio. Compreende os seguintes segmentos:

(a) Origem do nervo occipital maior - Emergindo entre o arco posterior do atlas e a lâmina subjacente do axis, mantendo estreita relação com a cápsula articular da articulação atlanto-occipital lateral, o segundo nervo cervical faz pequeno trajeto oblíquo em direção caudal e lateral sob o músculo obliquo inferior da cabeça. A este nível divide-se dando prigem a um ramo lateral e a um ramo medial que é o nervo occipital maior.

(b) Segmento intermuscular do nervo occipital maior - O nervo occipital maior contorna o músculo obliquo inferior da cabeça, enlaçando-o e descrevendo curva de concavidade superior, alcançando dessa forma plano superior ao de sua origem, e continua seu percurso sobre o ventre dos músculos oblíquo inferior da cabeça e reto posterior maior da cabeça. O percurso entre as faseias desses músculos é direcionado cranial e medialmente, descrevendo trajetória mais longa e mais verticalizada em relação à porção sob o músculo oblíquo inferior da cabeça. Seguido por veias satélites, o nervo perfura o ventre do músculo semiespinhoso da cabeça em sua porção medial, à meia distância entre a linha superior da nuca e o vértice do ângulo formado pelo ligamento nuca! e a borda medial do músculo esplênio da cabeça, cobertos pela aponeurose do músculo trapézio, o nervo occipital maior e a veia occipital, agora em plano mais superficial, continuam o percurso em direção cranial e lateral.

(c) Emergência subcutânea do nervo occipital maior - A artéria occipital emerge entre os músculos esternocleidomastóideo e esplênio da cabeça depois de descrever sinuoso trajeto entre eles. Junta-se à veia e ao nervo e, em seguida, esse conjunto vásculo-nervoso atravessa a aponeurose do trapézio ao nível do terço médio da linha entre o processo mastóide e a protuberância occipital. Na região da emergência cutânea, antes do conjunto vásculo-nervoso atravessar a aponeurose do trapézio, a veia occipital constitui um plexo maior.
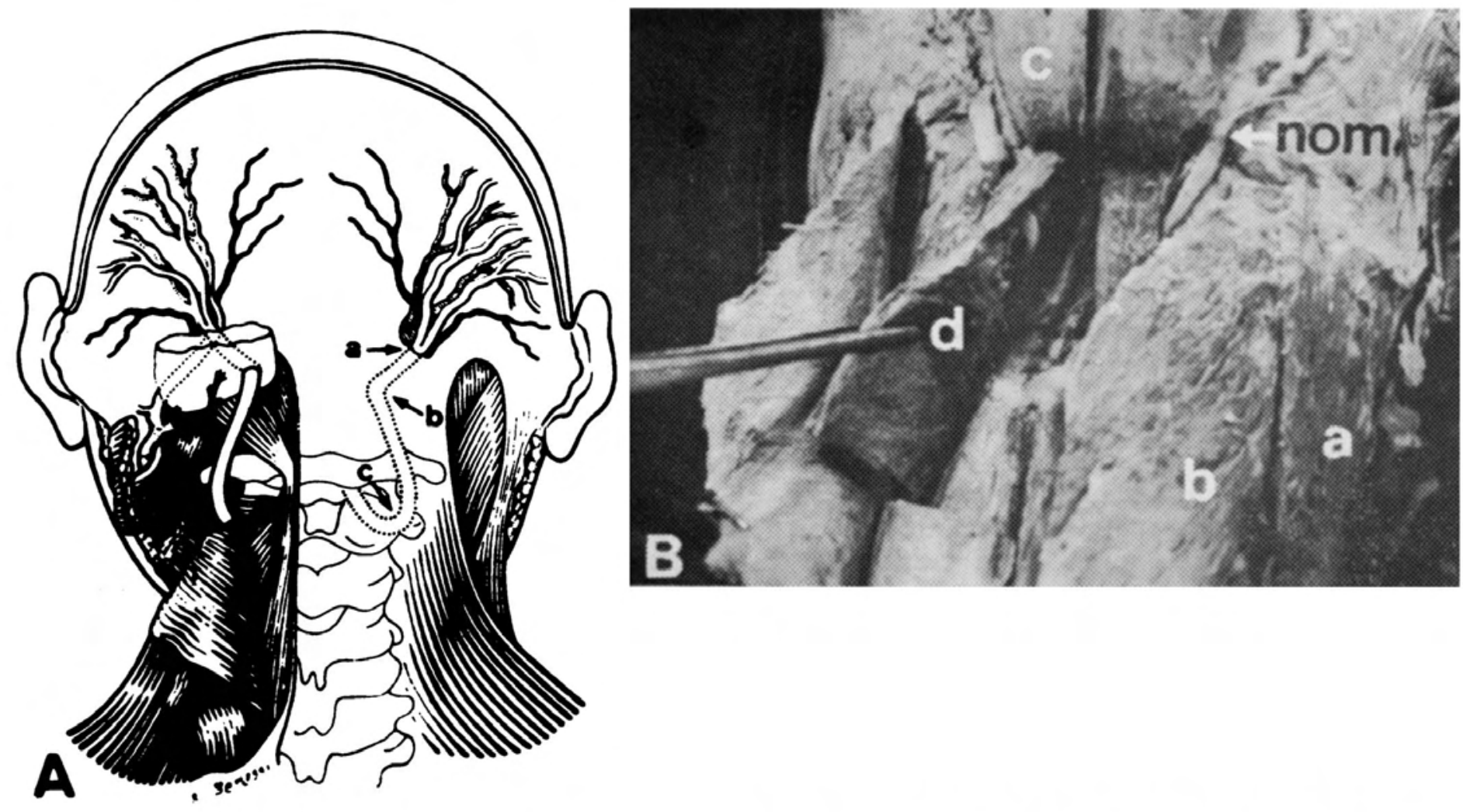

Fig. 1 - Em A, as setas indicam os pontos criticos na etiologia da dor occipital: (a) região em que o nervo occipital maior perfura aponeurose do músculo trapézio para alcancar a tela subcutanea. Ao longo de sua estratigrafia, o nervo descreve dois angulos com mudanças de direção; um relacionado ao músculo semi-espinhoso da cabeça (b) $e$ outro, ao músculo obliquo inferior da cabeca (c).

Em B, aspecto macroscópico do trajeto do nervo occipital maior (NOM) em seu segmento intermuscular: a seta indica o local de emergencia subcutanea do NOM entre os músculos esternocleidomastoideo (a) e esplenio da cabega (b); músculo trapézio (c); músculo semiespinhoso (d). 


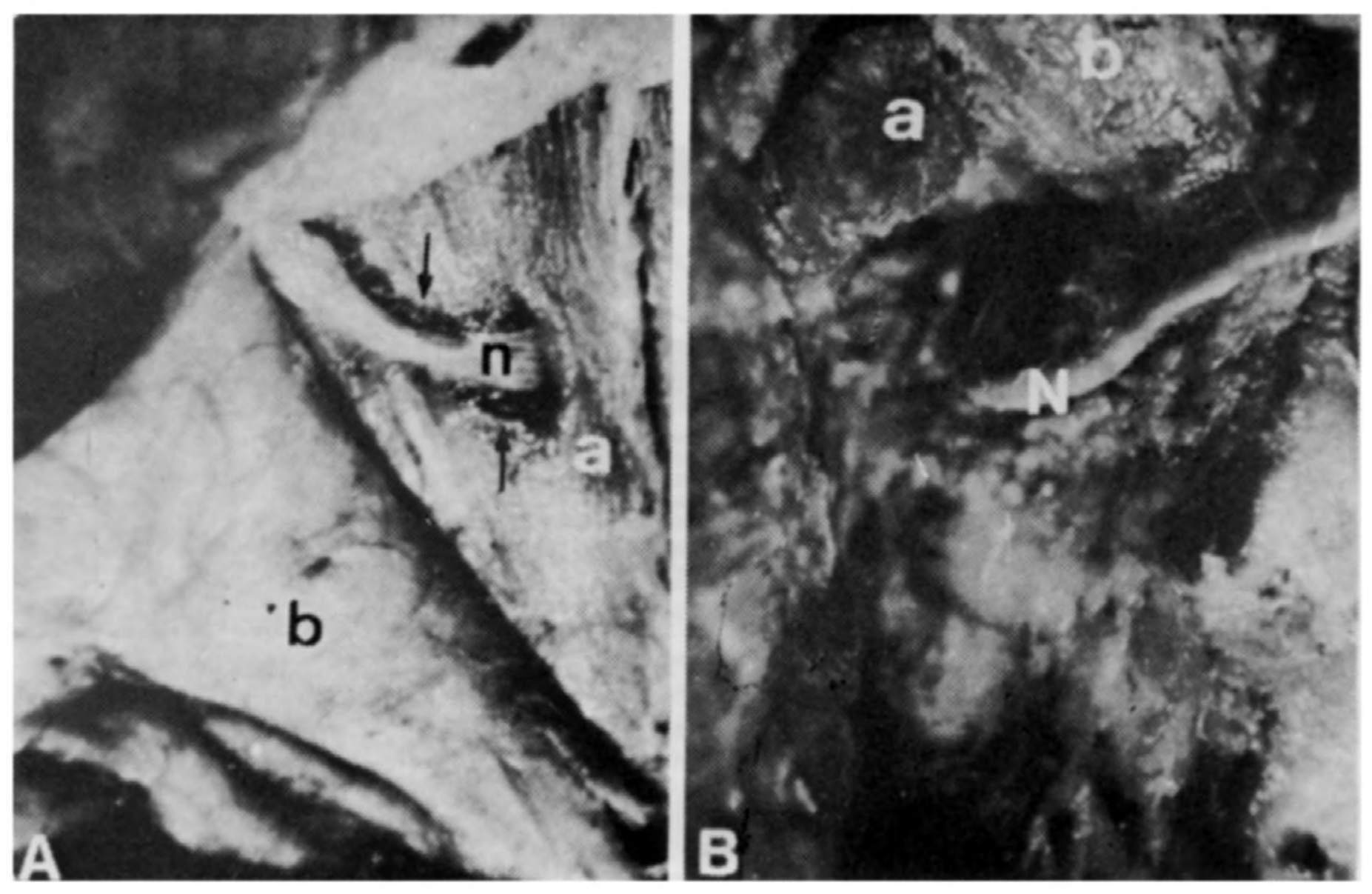

Fig. 2-Em A, emergência do nervo occipital maior (n) por entre as fibras do músculo semi-espinhoso da cabeça (a) seguido por veias satelites (setas); o músculo trapézio está rebatido lateralmente (b).

Em $B$, emergencia do ramo medial do segundo nervo cervical: músculo obliquo inferior da cabeca rebatido latenalmente (a); musculo reto posterior maior da cabega (b); nervo occipital maior (N).

2.

subcutâneas no plano supra-aponeurótico do trapézio. Na região em que o conjunto vásculo-nervoso perfura a aponeurose do trapézio, a veia ramifica-se, tornando seu trajeto independente dos demais componentes. A artéria, que continua descrevendo sinuosidades, e o nervo ramificam-se, mantendo intimas relações entre seus ramos. Estas ramificações continuam mantendo a direção cranial e lateral.

B. Estudo mesoscópico por cortes seriados espessos da região da emergência subcutânea do nervo occipital maior - Nos cortes sequenciais da região da emergência subcutânea do nervo occipital maior nota-se que. os envoltórios fibrosos dos componentes vásculos-nervosos comportam-se da seguinte forma:

1. Tecido colágeno - Este tecido espessa-se na região da emergência subcutânea do nervo occipital maior; esse espessamento separa os elementos do feixe vásculo-nervoso da faseia do músculo semi-espinhoso da cabeça de um lado e da aponeurose do trapézio do outro lado, constituindo estruturalmente bainha ou túnel de colágeno envolvendo o conjunto vásculonervoso. Feixes de fibras provenientes do perimísio e do epimisio do músculo semi-espinhoso dirigem-se à superfície externa dessa bainha, da superfície interna destacando-se lâminas fibrosas para o interior do túnel de colágeno, em forma de septos que se interpõem aos ramos nervosos e à artéria, enlaçando essas estruturas. Grande condensação de tecido colágeno é observada na região em que essas lâminas se destacam da bainha e nas regiões em que essas lâminas mudam de direção.

2. Tecido elástico - Examinando-se a bainha nota-se apenas a presença de pequena quantidade de malhas frouxas de tecido elástico na superfície interna. Os feixes de tecido elástico são mais condensados na região de que emanam os septos de separação das estruturas vásculo-nervosas.

Ver figuras 1 a 3 . 

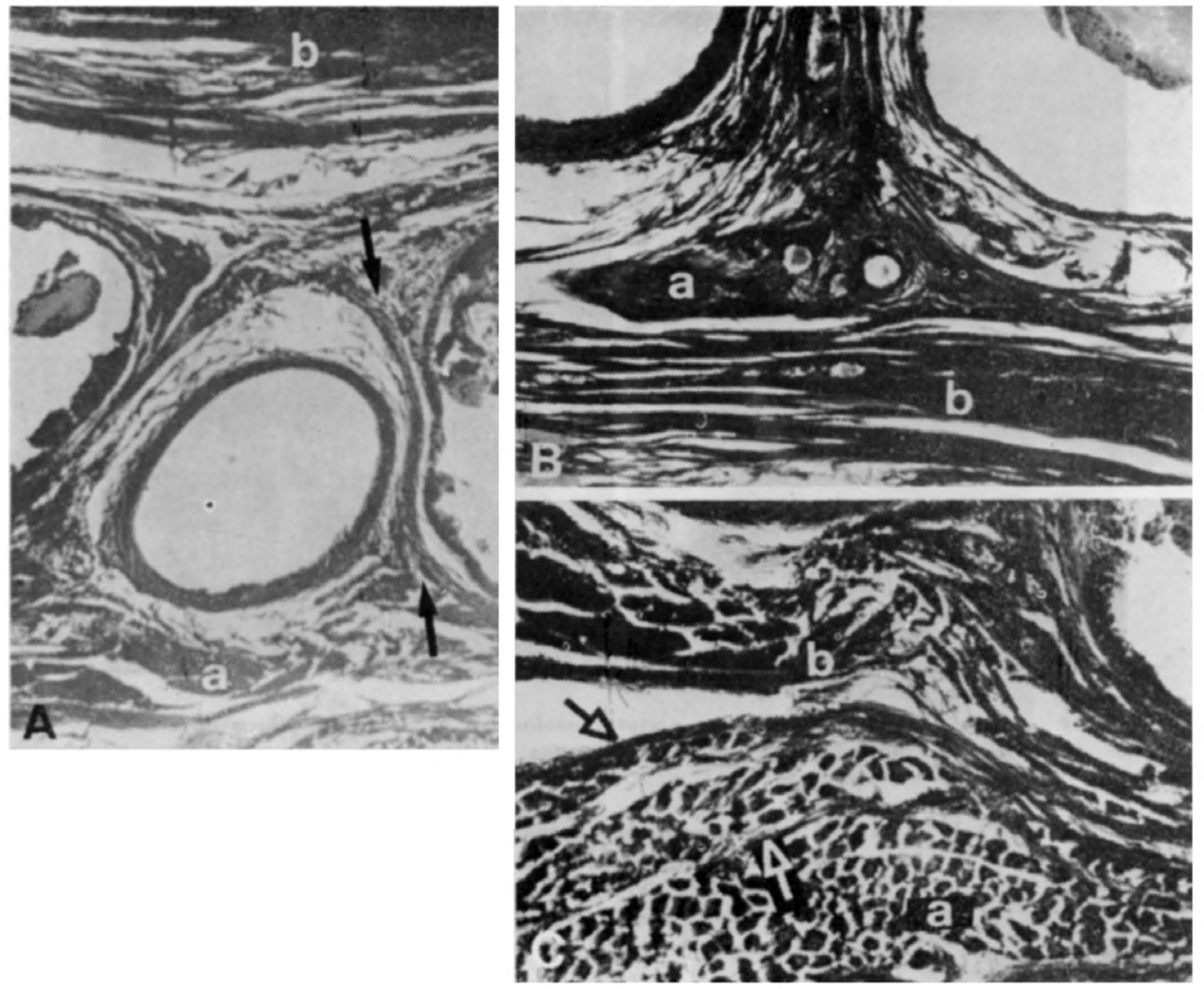

Fig. 3 - Região da emergência subcutanea do nervo occipital maior.

Em A: o tecido conjuntivo apresenta um espessamento que separa as estruturas do feixe vasculo-nervoso da fascia do músculo semi-espinhoso da cabega de um lado (a) $e$ da aponeurose do trapézio do outro lado (b), constituindo estruturalmente túnel de colágeno de onde destacam-se laminas fibrosas para o seu interior (setas), em forma de septos que se interpóm aos elementos do feixe vásculo-nervoso, enlaçando essas estruturas.

Em R: coxim fibroso (a) interposto entre os elementos do feixe vásculo-nervoso, próximo à superficie externa da bainha de colágeno (b).

Em $C$ : feixes de fibras provenientes do perimisio (seta branca) e do epimisio (seta preta) do músculo semi-espinhoso da cabega (a) dirigem-se à superficie externa da bainha de tecido colageno (b).

COMENTÁRIOS

A. ESTUDO MACROSCÓPICO DO TRAJETO DO NERVO OCCIPITAL MAIOR, DESDE SUA ORIGEM NO SEGUNDO NERVO CERVICAL ATÉ SUA EMERGÊNCIA SUBCUTÂNEA NA REGIÃO OCCIPITAL.

O território anatômico do nervo occipital maior foi descrito por vários autores.

Entre os clássicos, Rouvière'*, Cunningham 6, Testut e LatarjetiS, Lockhart e col. ${ }^{1 *}$ 8. Fra 
Com base em nossos resultados, poderíamos inferir que a posição prolongada em rotação da cabeça ou um aumento da excursão desse movimento representariam, para o nervo occipital maior ipsilateral ao movimento, um tríplice fator de comprometimento simultâneo, ou seja - (a) Compressão em seu trajeto entre as faseias e entre as fibras musculares, por espessamento do ventre dos músculos oblíquos inferior da cabeça, reto posterior maior da cabeça e semi-espinhoso da cabeça. As angulações sofridas pelo nervo ao contornar o músculo oblíquo inferior da cabeça e ao perfurar o músculo semi-espinhoso da cabeça podem constituir-se nos pontos mais críticos para estas compressões, (b) A tração do nervo, principalmente em seu percurso entre as faseias musculares. As mudanças de planos de percurso do nervo, a região em que o conjunto vásculo-nervoso emerge pela aponeurose do trapézio, as angulações que o nervo descreve ao perfurar o músculo semi-espinhoso da cabeça e ao enlaçar o músculo obliquo inferior da cabeça podem ser inferidas como pontos de apoio para a tração do nervo occipital maior, (c) Torção do nervo occipital maior no seu trajeto intermuscular. Considerando-se os pontos de apoio descritos no item b e as relações desse nervo com os músculos rotadores da cabeça, o nervo poderia sofrer torção longitudinal visto que, durante a rotação da cabeça, o deslocamento espacial de sua emergência aparente entre $\mathrm{Cl}$ e $\mathrm{C2}$ é menor que o de sua emergência subcutânea. Nossa análise desenrolou-se através de aspectos diferentes dos de Hunter e Mayfield w que discutiram a rotação da cabeça como agente de compressão do nervo occipital maior contralateral ao movimento. A estreita relação do segundo nervo cervical com a cápsula articular, descrita em nossos resultados, sugere que durante a rotação da cabeça o nervo contralateral à rotação acompanha o deslocamento capsular, afastando a possibilidade de compressão pelos arcos posteriores das vértebras.

A manutenção prolongada da posição de extensão ou rotação da cabeça poderia representar fator de compressão do nervo occipital maior em seu trajeto intermuscular pelo espessamento do ventre muscular dos músculos semi-espinhoso, oblíquo inferior e reto posterior maior da cabeça. Dimsdale 7 e Newill ${ }^{12}$ sugerem que o espasmo dos músculos posteriores do pescoço pode levar a cefaléia occipital. Assim como BogdukS, consideramos que a contração do trapézio, transmitindo a tensão de suas fibras para sua aponeurose, poderia também representar fator de tração do nervo occipital maior na região em que este perfura a aponeurose para alcançar a tela subcutânea. O plexo nervoso observado na região de emergência cutânea do conjunto vásculo-nervoso poderia constituir-se, a nosso ver, em fator compressivo sobre a artéria e o nervo em situações de turgescência venosa.

\section{B. ESTUdO MESOSCÓPICO POR CORTES SERIADOS ESPESSOS DA REGIÃO DA EMERGÊNCIA SUBCUTÂNEA DO NERVO OCCIPITAL MAIOR.}

As relações de continuidade e contiguidade entre o perimísio e o epimísio do músculo semi-espinhoso da cabeça e a bainha que contorna o conjunto vásculo-nervoso poderiam atuar como importante fator anticompressivo, protegendo os componentes vásculo-nervosos contra a expansão do ventre muscular. No entanto, em se entendendo o processo simultâneo de compressão, tração e torção, estas relações poderiam dificultar o delizamento do nervo sobre a faseia muscular durante o espessamento do músculo.

A grande condensação de tecido colágeno em locais determinados no interior da bainha vásculo-nervosa parece preencher os claros que estruturas cilíndricas, os nervos, ladeando outras de menor calibre, as artérias, deixam entre si. Estes espessamentos do tecido colágeno formam verdadeiros septos, isolando as estruturas dentro da bainha.

Baseamos nossa discussão nos estudos macro e mesoscópicos mencionados nos resultados sem, contudo, analisar isoladamente aqueles itens. Procuramos, assim, a visualização espacial da estrutura, diferentemente de procedimentos de outros autores. Acreditamos, sobretudo, que ao ampliarmos o conhecimento sobre essas estruturas, possamos oferecer substrato anatômico que contribua para a interpretação clínica da dor occipital.

\section{CONCLUSÕes.}

Os resultados obtidos nos estudos realizados permitiu-nos concluir que: (1) Topograficamente o nervo occipital maior divide-se em duas porções: profunda, que 
compreende origem e segmento intermuscular, e superficial, desde o ponto em que perfurou a aponeurose do músculo trapézio até suas ramificações terminais. (2) Ao tongo dessas duas porções, o nervo occipital maior descreve em sua estratigrafia dois ângulos com mudanças de direção: um relacionado ao músculo oblíquo inferior da cabeça e outro, ao músculo semi-espinhoso da cabeça, que podem representar pontos críticos na etiologia da dor occipital. (3) O nervo occipital maior, na região de transição de suas porções profunda e superficial, forma com a artéria e a veia occipital um feixe vásculo-nervoso superficial cercado por bainha de tecido conjuntivo fibroso. (4) Na constituição da bainha predomina o tecido colágeno que emite septos que separam os elementos constituintes do feixe, sendo conspícuo ao redor do epineuro. (5) A parede externa da bainha mantém íntima relação com o epimísio adjacente, trocando com este e com o perimísio feixes de fibras colágenas. (6) O tecido elástico está presente, predominantemente, na superfície interna da bainha, de onde se irradia de forma diferente entre os elementos do feixe.

Agradecimento - Os autores gostariam de expressar seu agradecimento ao Dr. Edgard Raffaelli Jr. pelas críticas e sugestões feitas na realização deste trabalho.

\section{REFERÊNCIAS}

1. Bärtschi-Rochaix W. Headache of cervical origin. In Vinken PJ, Bruyn GW: Handbook of Clinical Neurology. Vol 5 (Headache and Cranial Neuralgias). Amsterdam: North Holland, 1968, p 192-207.

2. Bogduk N. The anatomy of occipital neuralgia. Clin Exper Neurol 1980, 17:167-184.

3. Bogduk N. The clinical anatomy of the cervical dorsal rami. Spine 1982, $7: 319-330$.

4. Bogduk N, Corrigan B, Kelly P, Schneider G, Farr R. Cervical Headache. Med J Australia 1985, 143:202-207.

5. Carpenter MB. Neuroanatomia Humana. Ed 7. Rio de Janeiro: Interamericana, 1978, p 157.

6. Cunningham DJ. Anatomia Humana. Ed 8. Barcelona: Manuel Martin Editor, 1949, T 2, p 1126-1127.

7. Dimsdale H. Occipital headache. Practioner 1960, 105:110-112.

8. Gray H. Gray's Anatomy. Ed 35. London: Longman, 1973, p 1032.

9. Hollinshead WH. Livro Texto de Anatomia Humana. São Paulo: Harper \& Row do Brasil, 1980, p 822 .

10. Hunter CR, Mayfield FH. Role of the upper cervical roots in the production of pain in the head. Am J Surg 1949, 78:743-751.

11. Lockhart RD, Hamilton GF, Fyfe FW. Anatomy of the Human Body. London: Faber and Faber, 1959, p 274.

12. Newill RGD. Headache and giddiness of cervical origin. J R Coll Gen Practioners 1972, 22:51-53.

13. Poirier P, Charpy A. Traité d'Anatomie Humaine. Ed 2. Paris: Masson, 1907, T 3, p 1904.

14. Rouvière H. Anatomie Humaine Descriptive et Topographique. Ed 6. Paris: Masson, 1948, T 1, p 287.

15. Sjaastad O, Fredriksen TA, Stolt-Nielsen A. Cervicogenic headache, C2 rhyzopathy and occipital neuralgia: a connection? Cephalalgia 1986, 6:186-195.

16. Sjaastad O, Saunte C, Hovdahl H, Breivik H, Gronbaek E. «Cervicogenic» headache Cephalalgia 1983, $3: 249-256$.

17. Tandler J. Tratado de Anatomia Sistemática. Barcelona: Salvat 1933, p 369.

18. Testut L, Latarjet A. Tratado de Anatomia Humana. Barcelona: Salvat, 1951, T 3 p 255.

19. Voss H, Herrlinger R. Anatomía Humana. Ed 2. Buenos Aires: Ateneo, 1968, T1p 370

20. Zaitseva P, Chudnovsky HA. Characteristics of the topographical anatomical interrelatives of the vertebral artery, muscles and connective tissue, and neural formations in the area of the atlanto-occipital joint. Ark Anat Histol Embryol 1983, 84:23-29. 